\title{
Gedung Pertunjukan Seni Tradisional Pekalongan Sebagai REPRESENTASi Citra KaWASAN Jetayu
}

\author{
Amrina Rosyada, Muhammad Asrori, Samsudi \\ Program Studi Arsitektur \\ Jurusan Arsitektur Fakultas Teknik \\ Universitas Sebelas Maret Surakarta \\ Email : rosyada1791@gmail.com
}

\begin{abstract}
The theater in Pekalongan as image representation Jetayu area is a building that facilitates the activities of traditional art performances Pekalongan, including dance, theater, music and craftsmanship. The building is planned to be in Jetayu region, an area in the old town of Pekalongan which has a function as a social and cultural areas. The problem that appears is how to strengthen its image as a socio-cultural areas through the provision of traditional art container, which is based on the needs of the city will be the facility's appreciation of traditional art and also able to represent the visual image of the area. In maintaining harmony in the area of visual culture and support the activities contained, planned design concept using contextual architecture of the display area of the visual characteristics such as the Dutch colonial building, and the application of acoustic systems to support arts activities that accommodated. As a result, the building is expected to be a means of traditional performing arts facility that is adequate as well as being a reflection and cultural elements in the cultural area Jetayu in the application form and function of the building that takes into account the visual and aesthetic character raised by the region.
\end{abstract}

Keywords: Traditional Arts, Performance Building, image representation, Contextual Architecture.

\section{PENDAHULUAN}

Kesenian adalah salah satu unsur kebudayaan universal yang dimiliki setiap suku bangsa di Indonesia dan merupakan salah satu pusaka budaya. Kesenian memberikan sifat khusus yang membedakan bangsa Indonesia dengan bangsa lain dan membedakan suatu daerah dengan daerah lain di Indonesia.

Pertunjukan seni tradisional merupakan salah satu wahana untuk mencerminan kekayaan kebudayaan yang menjadi unsur bagian hidup masyarakat dan perwujudan norma-norma estetik-arstistik masyarakat.

Pekalongan merupakan salah kota di Jawa Tengah yang menjadi salah satu pintu gerbang masuknya pengaruh asing pada zaman pemerintahan kerajaankerajaan di Indonesia, seperti Dari India, Cina, Arab bahkan Eropa, menjadikan Pekalongan sebagai kota yang dihuni masyarakat dengan beragam etnis budaya, menjadikan proses akulturasi berperan besar dalam melahirkan perubahan dan transformasi dalam banyak bentuk tanggapan budaya. Beragam bentuk seni pertunjukan lahir dari akulturasi etnis budaya yang ada seperti seni tari, drama dan musik.

Dewasa ini kekayaan kesenian Pekalongan dalam pelestarian dan pengembangan mengalami kendala karena minimnya pementasan seni yang dapat dinikmati masyarakat yang seharusnya mengenal kesenian daerah. Salah satu kendala utama dalam kehidupan kesenian di Pekalongan adalah disebabkan terbatasnya sarana dan prasarana pendukung atau wadah untuk mementaskan dan mengembangkan kesenian yang ada.

Untuk mengantisipasi hal tersebut dalam melestarikan dan meningkatkan potensi kesenian tradisional di Pekalongan, Pemerintah Kota Pekalongan dalam hal ini lewat Dinas Pariwisata dan Kebudayaan maupun masyarakat membutuhkan sebuah wadah kultural yang mampu mempercepat proses bangkitnya kreativitas kebudayaan dan kesenian di Pekalongan, yaitu dengan adanya pemenuhan 
fasilitas berupa sebuah Gedung Seni Pertunjukkan.

Gedung Seni Pertunjukkan yang mampu menjadi wadah untuk memfasilitasi segala ekspresi, kreativitas dan kegiatan seni pertunjukan tradisional. Menampilkan beragam seni pertunjukkan yang rutin dan terkoordinir di Pekalongan sebagai wujud apresiasi, dilengkapi dengan standar sistem akustik, pencahayaan, tata panggung yang memadai dan berkualitas. Hal itu akan mendorong para seniman untuk dapat menampilkan sebuah pertunjukkan seni yang berkualitas pula.

Gedung Seni Pertunjukkan di Pekalongan ini direncanakan berada di Kawasan Jetayu, merupakan salah satu kawasan kota lama dilindungi oleh Peraturan Daerah yang mempunyai fungsi sebagai kawasan sosial budaya di Pekalongan, tertulis dalam Peraturan Daerah RTRW Kota Pekalongan bab 5 pasal55 ditulis;

"Kawasan Strategis Kota dari sudut kepentingan sosial budaya sebagaimana dimaksud dalam Pasal 55 ayat (1) huruf b, adalah kawasan kota lama Jetayu, yang terdiri atas:

a) kawasan cagar budaya sekitar Lapangan Jetayu di Kelurahan Panjang Wetan Kecamatan Pekalongan Utara sebagai kawasan heritage, dimana terdapat aset bangunan bersejarah yang harus dilindungi dan dilestarikan;".

Lingkungan kawasan tersebut dibingkai oleh bangunan-bangunan dengan berbagai bentuk seni Arsitektur Kolonial peninggalan Belanda yang masih terjaga dan difungsikan.

Kawasan Jetayu dalam Peraturan Daerah mengenai RTRW Kota Pekalongan memiliki ketentuan-ketentuan untuk diperbolehkan adanya pembangunan sarana-prasarana yang dapat menyesuaikan lingkungan dan menunjang fungsi kawasan sebagai kawasan budaya. Ketentuan tersebut memberi kesempatan Kawasan Jetayu untuk terus dikelola dan dikembangkan sebagai icon kawasan untuk kegiatan sosial budaya Pekalongan.

Oleh karena itu, dalam upaya penguatan dan merepresentasi citra Kawasan Jetayu, Gedung Seni
Pertunjukkan Tradisional yang direncanakan, perlu rancangan yang konstekstual terhadap tampilan kawasan agar terjaga keharmonisan visual kawasan dan mampu merepresentasikan citra visual Kawasan Jetayu, baik lewat material, bentuk atau simbol yang kental dengan ciri visual berupa bangunan kolonial peninggalan Belanda. Hal ini karena pengaplikasian representasi dalam bentuk, tidak terlepas dari konteks historis dan sosial yang terkait pada lingkungan sekitarnya. Adanya Gedung Seni Pertunjukkan Pekalongan di kawasan budaya Jetayu, diharapkan bukan sekadar hanya pemenuhan fasilitas, namun juga diharapkan ada pengembangan kesenian sebagai institusi maupun nilai.

\section{METODE}

Metode pembahasan yang dilakukan untuk tahapan pembuatan konsep Gedung Seni Pertunjukan Pekalongan sebagai representasi citra Kawasan Jetayu adalah sebagai berikut.

1. Penelusuran Masalah

Tahap penelusuran masalah merupakan ide awal untuk mengangkat tema/topik yang terpilih untuk penulisan konsep Gedung Seni Pertunjukkan Pekalongan sebagai representasi citra Kawasan Jetayu.

2. Pengumpulan Data

\section{a. Data Primer}

Data primer didapat dari studi literatur, yang merupakan tahapan mencari informasi melalui bukubuku referensi, laman, atau hasil penelitian yang terkait dengan judul. Studi literatur tersebut adalah sebagi berikut.

1) Tinjauan kota yang mendukung Gedung Seni Pertunjukkan Pekalongan sebagai representasi citra Kawasan Jetayu

2) Peraturan/kebijakan tentang bangunan gedung di Kawasan Jetayu Pekalongan

3) Teori arsitektur kontekstual

4) Data tentang potensi seni budaya, arsitektur, dan wisata yang berkaitan dengan Gedung Seni Pertunjukkan Pekalongan 
sebagai representasi citra Kawasan Jetayu

b. Data Sekunder

1) Wawancara

Wawancara

merupakan

pengumpulan informasi dan data

dengan pihak-pihak terkait

sebagai bahan referensi dan acuan dalam menyusun konsep.

2) Survey Lapangan

Metode survey lapangan bertujuan mengetahui kondisi di lapangan mengenai karakteristik dari tapak perancangan.

3) Dokumentasi

Merupakan foto-foto atau rekaman dari obyek yang menjadi tujuan studi observasi untuk menambah kelengkapan data dan memudahkan penjelasan obyek.

3. Analisis Pendekatan Arsitektur Kontekstual

Menggunakan metode analisa deskriptif yaitu melalui penguraian data yang disertai gambar sebagai media berdasar pada teori normatif yang ada serta bagan-bagan alur. Tahapan analisa merupakan tahap pengolahan data yang telah terkumpul dan dikelompokkan berdasarkan pemrograman fungsional, performansi, dan arsitektural.

4. Sintesa

Tahap sintesa penyatuan antara keseluruhan data dan hasil analisa untuk mencapai tujuan dan sasaran yang telah ditetapkan. Data dan analisa diolah dengan ketentuan dan persyaratan perencanaan dan perancangan yang pada akhirnya seluruh hasil olahan dikembangkan menjadi konsep rancangan yang siap ditransformasikan pada bentuk fisik yang dikehendaki.

5. Konsep Perencanaan dan Perancangan

Dari proses analisa dan sintesa arsitektural akan dihasilkan beberapa konsep yaitu konsep lokasi dan tapak, konsep peruangan, konsep tampilan bangunan, konsep utilitas dan struktur pada Gedung Seni Pertunjukkan Pekalongan
3. ANALISIS

3.1 Analisis Pelaku dan Kegiatan

1. Analisis Pelaku Kegiatan Pelaku kegiatan terdiri dari pengunjung, seniman, dan pengelola.

2. Analisis Kegiatan

1) Kegiatan utama

a) Kegiatan pentas indoor

b) Kegiatan pentas outdoor

c) Kegiatan latihan

d) Kegiatan diskusi seniman

2) Kegiatan penunjang

3) Kegiatan pengelola

4) Kegiatan servis

\subsection{Analisis Besaran Ruang}

Tabel 1. Rekapitulasi Kebutuhan Ruang

\begin{tabular}{lll}
\hline & $\begin{array}{l}\text { Kelompok } \\
\text { Kegiatan }\end{array}$ & $\begin{array}{l}\text { Besaran Ruang } \\
(\mathrm{m} 2)\end{array}$ \\
\hline 1. & Penerimaan & 144 \\
2. & Utama & 1859.55 \\
3. & Penunjang & 107.8 \\
4. & Pengelola & 368.8 \\
5. & Parkir dan servis & 3077.12 \\
\hline & TOTAL & $5557.25 \mathrm{~m}^{2}$ \\
\hline
\end{tabular}

3.3 Analisis Pemilihan Lokasi Tapak

Lokasi terpilih berada di Kawasan Jetayu, merupakan kawasan dengan fungsi citra budaya di Pekalongan. Kawasan Jetayu telah memenuhi Karakteristik penentuan lokasi terkait kontekstual, yaitu:

- Tingkat pencapaian ke lokasi sangat baik

- Lingkungan yang mempunyai nilai historis yang tinggi

- Lingkungan yang mempunyai jiwa tempat dan karakter kota

- Lokasi yang memiliki rencana pembangunan pesat kedepannya, sehingga pembangunan didalamnya dapat kontekstual. 


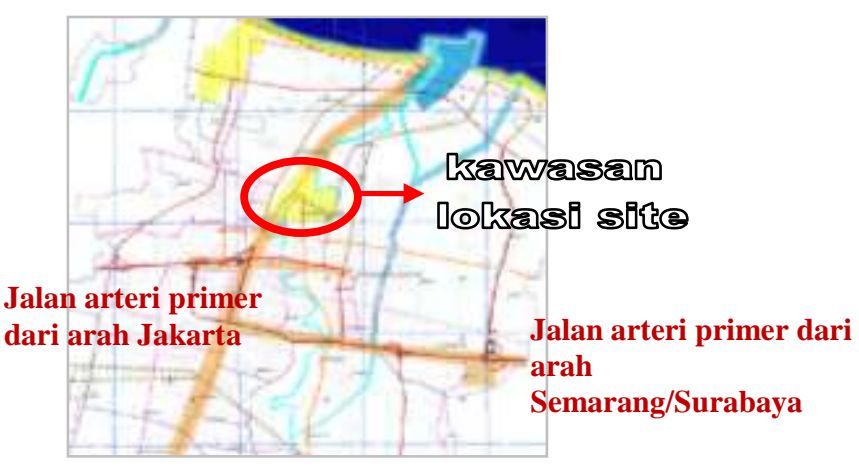

Gambar 1. Pencapaian Lokasi Tapak

Kawasan Jetayu sangat mudah dijangkau dari berbagi arah Kota Pekalongan, baik melalui jalan arteri primer kota, dari arah barat maupun timur, karena Kawasan Jetayu merupakan area pusat Kota Pekalongan.

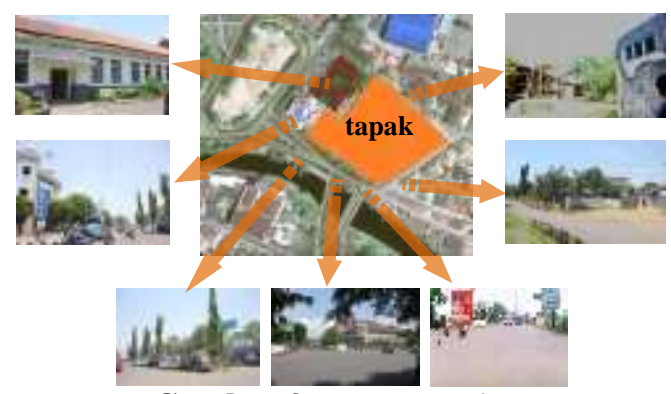

Gambar 2. Batas Tapak

Batas tapak:

Utara : Pemukiman Penduduk

Selatan : Jembatan Sungai Lodji, Jalan Rajawali

Timur $\quad$ : Masjid, Museum Batik

Pekalongan

Barat : Pemukiman Penduduk

\subsection{Analisis Pencapaian Tapak}

Tapak dikelilingi oleh 3 akses jalan, jalan utama bagian selatan, dan jalan lingkungan di sisi bagian timur dan barat. Ketiga jalan tersebut dimanfaatkan sebagai akses untuk masuk dan keluar tapak dengan pembagian sirkulasi untuk pengunjung dan pengelola. Pencapaian ke dalam bangunan harus mudah diakses, mudah dilihat dan memiliki sirkulasi yang aman akan menstimulus orang untuk masuk dalam area bangunan

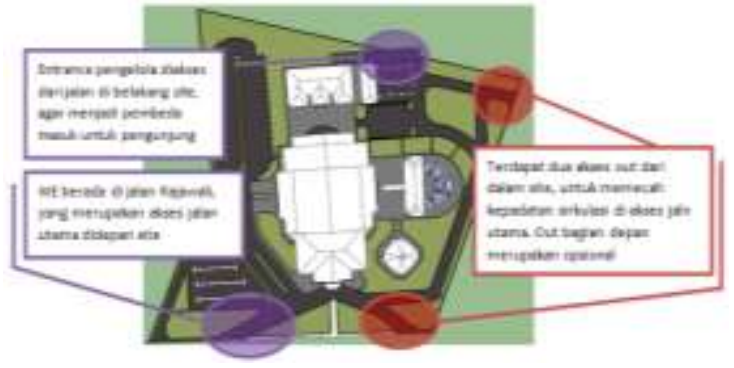

Gambar 3. Pola Pencapaian

\subsection{Analisis Pemintakatan}

Pemintakatan didasarkan pada beberapa pertimbangan khusus seperti analisis pencapaian, orientasi, pergerakan matahari, dan pengaruh lingkungan terhadap fungsi dari kegiatan yang akan diwadahi untuk menghasilkan penempatan ruang yang optimal dan konteks terhadap lingkungan yang ada.

Tabel 2. Persyaratan Ruang

\begin{tabular}{|c|c|c|}
\hline $\begin{array}{l}\text { Kelompok } \\
\text { Kegiatan }\end{array}$ & Nama Ruang & Keterangan \\
\hline \multirow{3}{*}{$\begin{array}{l}\text { Kegiatan } \\
\text { Penerimaan }\end{array}$} & Hall & \multirow{3}{*}{ Area Publik } \\
\hline & Informasi & \\
\hline & Loket & \\
\hline \multirow{2}{*}{$\begin{array}{l}\text { Kegiatan } \\
\text { Penunjang }\end{array}$} & Snack retail & \multirow{2}{*}{$\begin{array}{l}\text { Area Semi } \\
\text { Publik }\end{array}$} \\
\hline & Mushala & \\
\hline \multirow{5}{*}{$\begin{array}{l}\text { Kegiatan } \\
\text { utama }\end{array}$} & Pentas indoor & \multirow{5}{*}{ Area Publik } \\
\hline & Pentas outdoor & \\
\hline & Tempat latihan & \\
\hline & Ruang pameran & \\
\hline & Ruang diskusi & \\
\hline \multirow{5}{*}{$\begin{array}{l}\text { Kegiatan } \\
\text { Pengelolaan }\end{array}$} & R .pimpinan & \multirow{5}{*}{ Area Privat } \\
\hline & R. bagian admin & \\
\hline & R . bagian humas & \\
\hline & $\begin{array}{l}\mathrm{R} \text {. bagian sarana } \\
\text { prasarana }\end{array}$ & \\
\hline & R . bagian artistic & \\
\hline \multirow{5}{*}{$\begin{array}{l}\text { Kegiatan } \\
\text { service }\end{array}$} & Parkir & \multirow{5}{*}{ Zona Privat } \\
\hline & Keamanan & \\
\hline & Kebersihan & \\
\hline & Teknisi & \\
\hline & Pantry & \\
\hline
\end{tabular}




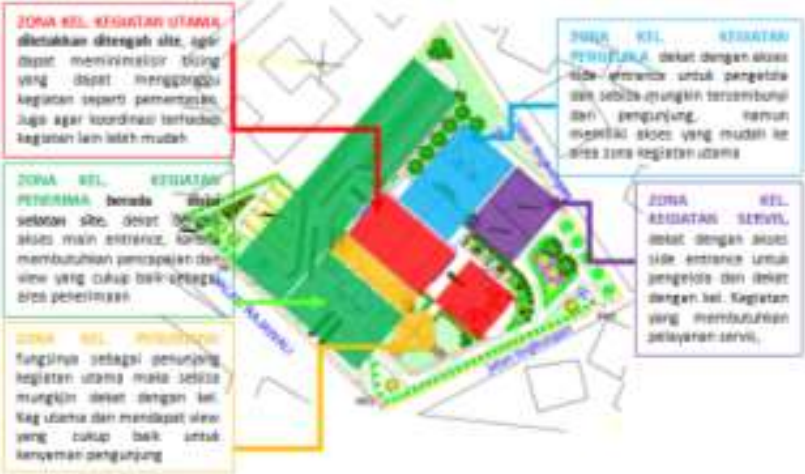

Gambar 4. Pemintakatan Pada Tapak

\subsection{Analisis Langgam, Bentuk, dan Tampilan Bangunan}

\subsubsection{Analisis Langgam Arsitektur} Bangunan berdasarkan Kontekstual

Menurut Anthony V Antoniades, klasifikasi dari bidang konsteks dalam arsitektur dapat berhubungan dengan tapak dari lingkungan, kondisi bangunan sekitar, masyarakat, budaya, dan material di daerah setempat. (Brent C.Brolin, Architecture In Context, 1980. dalam Atmadi. Kontekstual Dalam Dialog Arsitektur. 2001)

Penerapan desain kontekstual yang harmoni pada Gedung Seni Pertunjukan diharapkan dapat membentuk satu kesatuan citra kontinuitas visual pada Kawasan Jetayu yang kental dengan ciri visual berupa bangunan kolonial peninggalan Belanda. Hal ini karena pengaplikasian representasi dalam bentuk, tidak terlepas dari konteks historis dan sosial yang terkait pada lingkungan sekitarnya.

\subsubsection{Analisis Bentuk dan Tampilan Bangunan}

Gedung seni pertunjukkan tradisional merupakan bangunan publik, sekaligus merupakan salah satu penguat citra yang merepresentasikan Kawasan Jetayu, maka bangunan gedung seni pertunjukkan tradisional memiliki karakter;

a. Massa yang terbuka, mengundang atau berkesan menerima

b.Monumental namun tetap dapat berinteraksi dengan lingkungan sekitar yaitu Kawasan Jetayu dengan menyeseuaikan elemen-elemen bangunan (proporsi, material, tekstur, komposisi bangunan)

c. Bangunan dengan massa bangunan tunggal untuk fungsi utama dan massa majemuk untuk fungsi lainnya. Secara fungsional kegiatan yang satu dengan yang diharapkan saling berinteraksi untuk menghidupkan suasana dari gedung seni pertunjukkan tradisional yang direncanakan.

Gedung seni pertunjukkan tradisional yang direncanakan berada di Kawasan Budaya Jetayu yang memiliki karakter visual bangunan Arsitektur Kolonial. Sebagai bentuk kontekstualisme terhadap Kawasan Jetayu sekaligus bentuk representasi sebagi kawasan budaya, maka tampilan kolonial pada Gedung Seni Pertunjukkan sangat diperlukan agar terdapat harmonisasi visual antar bangunan yang tidak menimbulkan chaos karena perbedaan tampilan antar bangunan yang sangat ekstrim (kontras). Tampilan Arsitektur Kolonial bangunan gedung seni pertunjukan mengadopsi bentukan-bentukan kolonial pada bangunan-bangunan di sekitar kawasan, sebagai berikut:
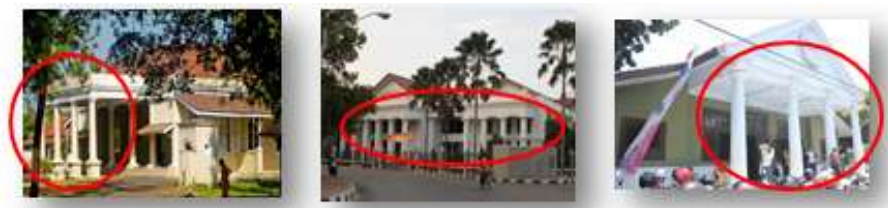

- Penggunaan tiang atau kolom bulat dan tinggi

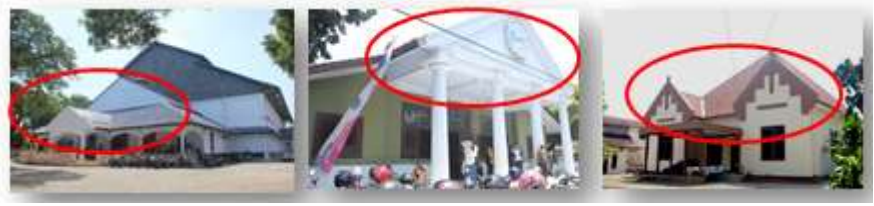

- Atap pelana dan gabel segitiga pada fasad
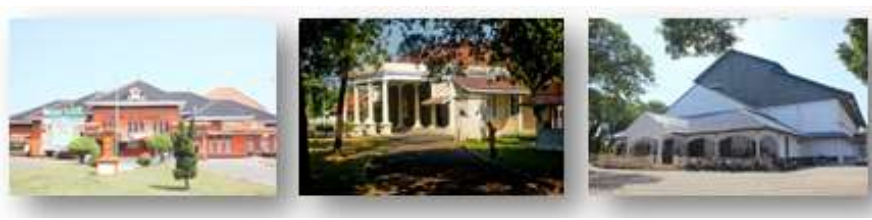
- Ruang luar yang luas pada area depan bangunan

Gambar 5. Bangunan-Bangunan Kolonial di Kawasan Jetayu

\subsection{Analisis Persyaratan Ruang Pertunjukkan Seni Tradisional \\ 3.7.1 Bentuk Ruang Pentas}

Bentuk pentas panggung yang paling banyak memungkinkan untuk mewadahi kegiatan seni pertunjukan yang direncanakan dalam gedung seni pertunjukan tradisional Pekalongan adalah bentuk Tipe Melingkar $210^{\circ}-220^{\circ}$ atau menyerupai bentuk tapal kuda. Bentuk ini juga mampu merangsang keinginan untuk melakukan kontak karena mempunyai karakter mengikat, stabil, mengundang, dan menimbulkan perasaan gerak yang kuat.

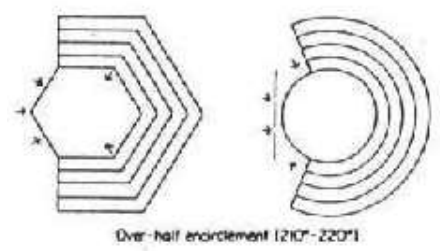

Gambar 6. Tipe Melingkar $210^{\circ}-220^{\circ}$ (Sumber: teaterku.files.wordpress.com)

Demi kualitas pentas yang baik, ruang pentas indoor sepenuhnya tidak tertutup dengan dinding yang massive, hal ini untuk menyalurkan gelombang suara panjang dari musik tradisional.

Pada pementasan outdoor, menurut Doelle (Akustik Lingkungan, 1990), hal yang harus diperhatikan adalah bahwa;

- panggung dinaikkan dari lantai penonton yang paling depan

- bagian penonton bertangga curam

\subsubsection{Akustik Ruang Pentas}

1.Lantai

a. Lantai Panggung

Agar semua penonton dapat meyaksikan pertunjukan, lantai panggung dibuat perbedaan tinggi berkisar setengah ketinggian badan manusia umumnya 70-90 cm.

Pada panggung yang terletak dalam ruang tertutup, lantai panggung dilapisi dengan bahan tebal lunak yang mampu meredam bunyi seperti penggunaan karpet tebal atau gabus yang dilapisi lantai parquette.

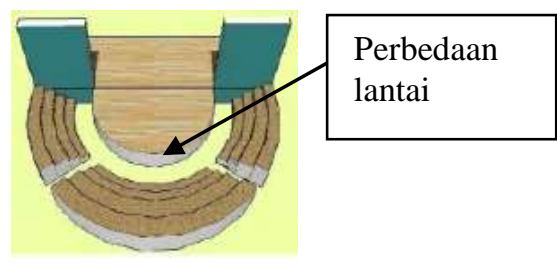

Gambar 7. Perbedaan Lantai Pada Panggung Pentas Dan Lantai Penonton

(Sumber: teaterku.files.wordpress.com)

b. Lantai Penonton

Penataan kursi penonton dengan sistem lantai miring atau bertrap untuk menampung jumlah penonton dan menghindari desain memanjang dan lantai dilapisi bahan lunak agar mampu menyerap kebisingan

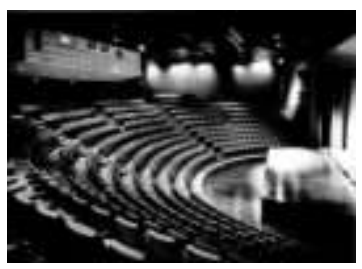

Gambar 8. Penataan Kursi Penonton Bertrap dan Melengkung

(Sumber: Doelle, Akustik Lingkungan, 1990)

2. Dinding

a. Dinding Panggung

Dinding belakang didesain relatif mendatar dengan bahan penyerap suara, agar tidak bias, atau dilapisi bahan pemantul suara seperti bahan glassfiber panel.

b. Dinding Penonton

- Desain dinding ganda, yaitu sebagai insulasi bunyi dari luar dan untuk meningkatkan kualitas bunyi dalam ruang.

- Area dinding penonton bagian belakang dirancang tidak untuk memantulkan bunyi agar tidak terjadi dengung.

- Dinding membentuk sudut melebar atau sejajar kearah 
penonton agar tidak terjadi cacat akustik.

- Dinding belakang penonton didesain melengkung.

3. Plafon

a. Plafon Panggung

Plafon panggung dilapisi dengan bahan yang memantulkan, agar pada keadaan tanpa peralatan sound system, suara pementas dapat disebar ke arah penonton. Area plafon juga dapat dijadikan area penempatan pencahayaan untuk panggung.
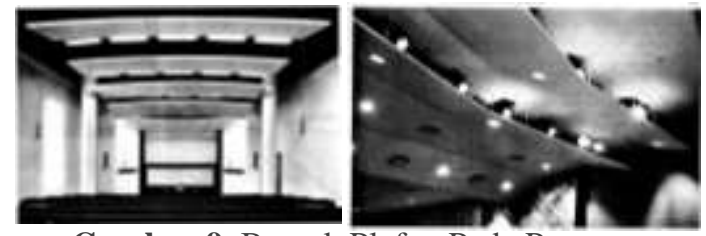

Gambar 9. Bentuk Plafon Pada Panggung (Sumber: Doelle, Akustik Lingkungan,1990)

b. Plafon Penonton

Bentuk plafon dapat berupa gerigi atau datar melengkung dan dilapisi bahan penyerap

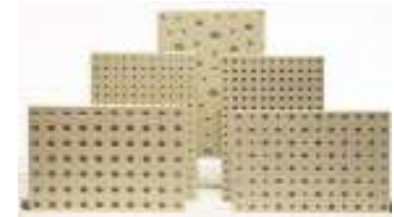

Gambar 10. Unit Akustik Untuk Plafon

(Sumber: www.acoustics.com )

\subsection{Analisa Struktur}

Struktur atap bangunan (upper structure) menggunakan rangka baja WF. Struktur badan (supper structure) yang digunakan adalah struktur rangka dinding dengan kolom dan balok sebagai pemikul beban. Pondasi yang dipilih sebagai sub structure adalah pondasi batu kali dan footplat.

\section{KESIMPULAN (KONSEP DESAIN)}

Gedung seni pertunjukan di Kawasan Jetayu mempunyai gagasan untuk dapat menguatkan citra kawasan dan ikut merepresentasikan kawasan sebagai kawasan budaya. Dalam mencapai hal tersebut, maka dibutuhkan perancangan yang kontekstual.

Beberapa strategi tampilan eksterior dan interior pada Gedung Seni Pertunjukan adalah melalui pendekatan kesesuaian visual. Koneksi visual antara sejarah dan latar belakang kawasan yang mendasari keberadaan bangunan-bangunan kolonial di sekitarnya. Koneksi visual tersebut diaplikasikan dengan penggunaan langgam Arsitektur Kolonial pada tampilan bangunan.

Dari berbagai komponen yang telah di analisis, maka dihasilkan beberapa keputusan desain seperti berikut:

Rencana Tapak Bangunan

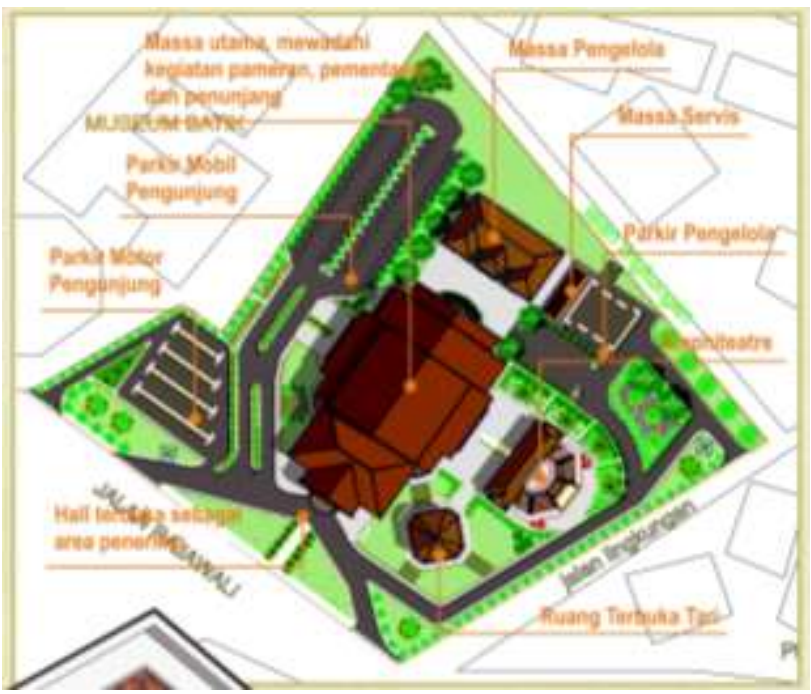

Gambar 11. Tata Letak Massa Bangunan Pada Tapak

Penataan massa bangunan pada tapak ini terbentuk dari berbagai analisis tapak dalam konsep kontekstual, seperti analisis ruang, tapak, bangunan, persyaratan ruang, sistem struktur dan sistem utilitas. Tata massa pada tapak juga merupakan hasil dari analisis dan pertimbangan berdasarkan keamanan, kemudahan akses, dan kenyamanan bagi pengguna dan pengunjung bangunan. 


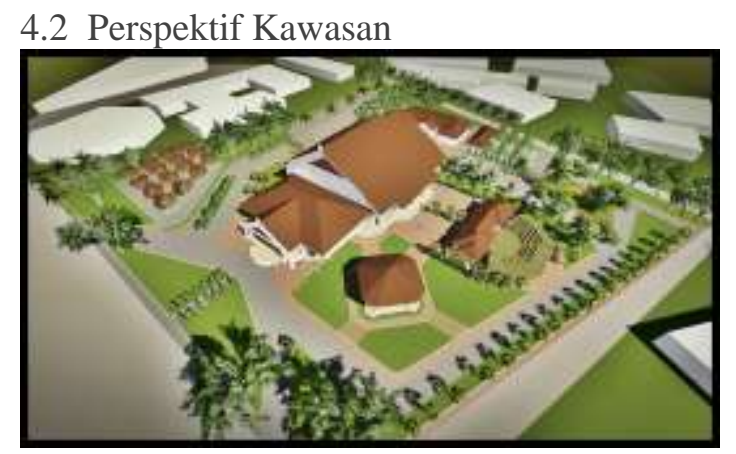

Gambar 12. Perspektif Bangunan Pada Tapak

\subsection{Eksterior Bangunan Utama}

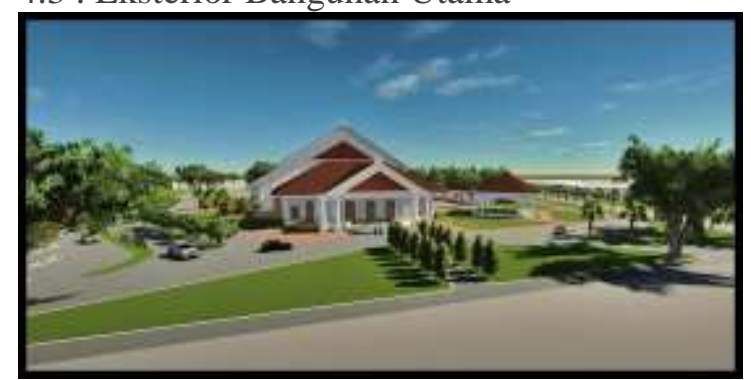

Gambar 13. Eksterior Bangunan Utama

Sisi timur kawasan yang bersebelahan dengan area pemukiman penduduk dibuat sebagai area publik terbuka dengan fasilitas seni yang dapat dinikmati masyarakat berupa ruang latihan terbuka dan amphieteater.

Ruang luar yang luas sebagai hall terbuka kawasan bangunan sekaligus sebagai jarak pandang dari area luar tapak ke bangunan agar bangunan terlihat monumental.

\subsection{Interior Ruang Pameran}

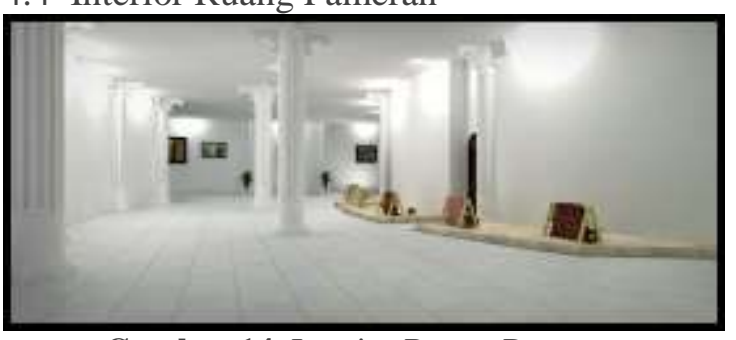

Gambar 14. Interior Ruang Pameran

Ruang pameran ini merupakan ruang display berbagai karya kesenian yang dibuat oleh seniman Kota Pekalongan dan produk kerajinan khas Pekalongan yang dibuat oleh masyarakat. Ruang ini sekaligus sebagai ruang transisi sebelum pengunjung memasuki ruang pentas.

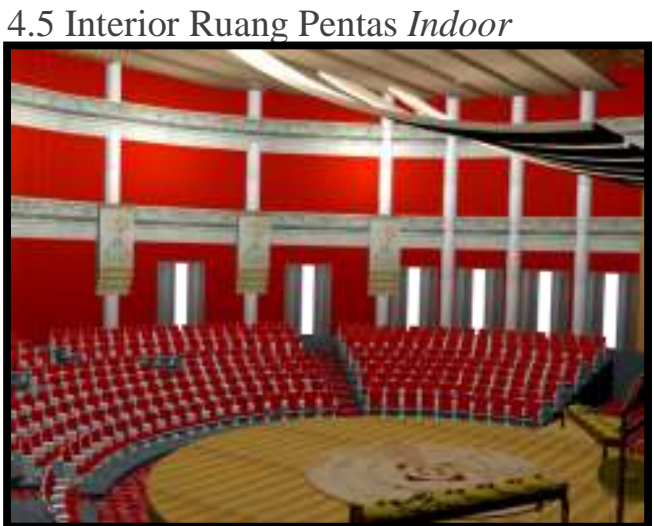

Gambar 15. Interior Ruang Pentas

Dalam mengatasi permasalahan

akustik, ruang pentas indoor dilapisi sistem akustik di tiap sisi dinding, lantai dan plafon. Namun untuk mengantisipasi gelombang panjang musik tradisional, dinding pada ruang pentas dibuat cukup fleksibel dengan penerapan pintu-pintu lipat yang dilapisi panel akustik yang dapat dibuka atau ditutup sesuai kebutuhan musik atau pertunjukan yang disajikan.

\subsection{Interior Ruang Latihan}

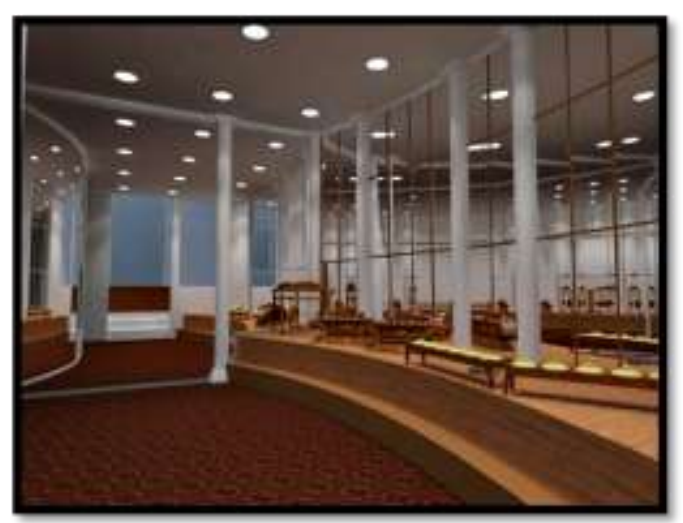

Gambar 16. Interior Ruang Latihan

\subsection{Interior Ruang Diskusi Seniman}

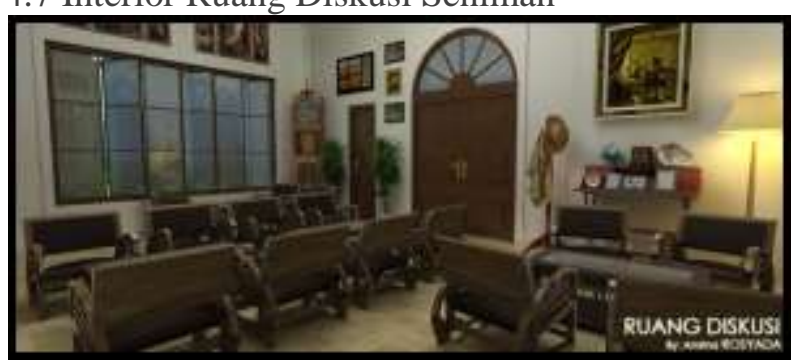

Gambar 17. Interior Ruang Diskusi Seniman 


\section{REFERENSI}

Atmadi, Parmono. 2001. Kontekstual Dalam

Dialog Arsitektur. Malang. Group

Konservasi Arsitektur \& Kota.

Doelle, Leslie L. 1992. Akustik Lingkungan.

Jakarta. Gramedia Pustaka Utama.

Peraturan Daerah RTRW 2009-2029 Kota

Pekalongan.

www.acoustics.com

teaterku.files.wordpress.com 